DOI: https://doi.org/10.24867/10KG02Bozinovic

\title{
VIZUALIZACIJA SENTINEL 3 SATELITSKIH SNIMAKA PRIMJENOM OPEN LAYERS BIBLIOTEKE
}

\section{VISUALIZATION OF SENTINEL 3 SATELLITE IMAGES USING THE OPEN LAYERS LIBRARY}

\section{Mara Božinović, Fakultet tehničkih nauka, Novi Sad}

\section{Oblast - GEODEZIJA I GEOMATIKA}

Kratak sadržaj - U radu je izvršena analiza snimaka, dobijenih sa Sentinel 3 platforme, u svrhu njihovog predstavljanja u obliku timeline-a na geoportalu. Primjer je prikazan na području Fruške gore (Vojvodina), gdje je pomoću vizualizacije geoprostornih podataka moguće pratiti promjene jednog područja tokom godine.

Ključne reči: Vizualizacija geoprostornih podataka, sateliti, Sentinel, Geoserver, Geoportal, OpenLayers 3, QGIS, SNAP, Evropska svemirska agencija

Abstract - In this paper an analysis of data, acquired by Sentinel 3 platform has been done. The analyses were made for the purposes of visualization of a timeline on a geoportal. As an example of the geospatial data visualization which can be used for monitoring, imagery of Fruška gora (Vojvodina) were analyzed.

Keywords: Geospatial data visualization, satellites, Sentinel, Geoserver, Geoportal, OpenLayers 3, QGIS, SNAP, European Space Agency

\section{UVOD}

Mnogi vizualizaciju geoprostornih podataka smatraju kartografijom, ali promjene koje su nastale poslednjih godina u smislu razvoja tehnologije i nauke su dovele do toga da se ova dva pojma više i ne mogu u potpunosti poistovijetiti. Činjenica je da se svet mapa i karata menja. Svjedoci smo važnih i dinamičnih promjena u oblastima prikupljanja, upravljanja, analiziranja, interakcije i vizualizacije velike količine geoprostornih podataka, u poslednje dvije decenije, a promjene će postati sigurno još brže i učestalije u budućnosti.

Tehnološki napredak doveo je do kvantitativnih i kvalitativnih promjena, koje se odnose na mape, njihovu proizvodnju i reprezentaciju. Proces vizualizacije predstavlja na neki način prevod konverzije geoprostornih podataka iz neke baze podataka u proizvod koji predstavlja neku vrstu mape.

Glavna karakteristika koja $\mathrm{u}$ ovom radu treba da bude predstavljena jeste timeline (time series) u okviru interfejsa geoportala. Timeline za geoprostorne podatke predstavlja prikaz (vizualizaciju) geoprostornih (geografskih) promena $\mathrm{u}$ toku nekog vremenskog perioda. Te promjene mogu biti

\section{NAPOMENA:}

Ovaj rad proistekao je iz master rada čiji mentor je bio doc. dr Dušan Jovanović. na primjer vizuelno praćenje topljenja leda na planinama, promjena vegetacije $\mathrm{u}$ toku godine, šumskih požara ili širenja bolesti. U ovom radu se za primjer i predstavljanje timeline (time series) vrši praćenje promjene vrijednosti NDVI (Normalized Difference Vegetation Index) indeksa tokom jedne godine.

\section{OSNOVNI POJMOVI DALJINSKE DETEKCIJE I KARAKTERISTIKE PRIMIJENJENIH SENTINEL 3 OLCI SNIMAKA}

\subsection{Princip rada daljinske detekcije}

Daljinska detekcija kao naučna disciplina se veoma intenzivno i brzo razvila zahvaljlujući savremenoj tehnologiji i postala nezamjenjiv način masovnog prikupljanja podataka o prostoru.

Daljinska detekcija predstavlja metod prikupljanja informacija putem sistema koji nisu u direktnom, fizičkom kontaktu sa ispitivanom pojavom ili objektom [1].

Osnovni elementi pasivne daljinske detekcije su:

- Izvor energije (A)

- Prostiranje i atmosfera (B)

- Interakcija sa objektom (C)

- Snimanje energije (D)

- Prenos i procesiranje (E)

- Interpretacija i analiza (F)

- Aplikacije (G)

Osnovni princip rada daljinske detekcije se zasniva na mjerenju određenog energetskog polja, odnosno elektromagnetne energije koja je emitovana od strane objekta koji se proučava. Karakteristike nekog objekta se mogu definisati korišćenjem reflektovanih ili emitovanih elektromagnetnih talasa od strane objekta, zato što svaki objekat ima jedinstvene karakteristike refleksije ili emisije [1].

\subsection{NDVI indeks (Normalized Difference Vegetation Index)}

Vegetacioni indeksi su kreirani da povećaju vegetacioni signal kombinujući informacije iz različitih talasnih opsega, stvarajući informaciju koja ne bi bila dostupna ni u jednom od pojedinačnih opsega.

Jedan od najviše korišćenih indeksa jeste NDVI (Normalized Difference Vegetation Index). Crveni i plavi dio spektra se jako absorbuje od strane fotosintetičkog pigmenta (hlorofil), dok se blisko-infracrvena svjetlost jako reflektuje od istog. Na osnovu ovog možemo donijeti zaključak o NDVI indeksu, koji je dobar pokazatelj da li 
biljka absorbuje veći dio svjetlosti (što bi značilo da ima dobar proces fotosinteze) ili ne (što ukazuje na to da biljki treba dodatna njega, hrana ili slično).

Formula za NDVI (Normalized Difference Vegetation Index) je data u nastavku [2]:

$$
\mathrm{NDVI}=\frac{(N I R-R e d)}{(N I R+R e d)}
$$

\subsection{Evropska svemirska agencija (ESA)}

Evropska svemirska agencija (engl. European Space Agency) skraćeno ESA, međuvladina je organizacija osnovana 1975. godine i posvećena istraživanju svemira. Sa 25 država članica i sjedištem u Parizu (Francuska), ESA u svijetu ima više od 2.000 zaposlenih.

ESA je razvila posebnu grupu satelita pod nazivom Sentinel, koji se koriste specijalno za potrebe Kopernikus programa.

Kopernikus je formiran kako bi obezbijedio tačne, pravovremene i jednostavno dostupne informacije, koje se mogu koristiti za razumijevanje i ublažavanje efekata globalnog zagrijavanja, pružanje sigurnosti ljudima kao i uopšteno praćenje promjena u životnoj sredini koje mogu uticati na čovjeka.

Sentinel 3 sistematski mjeri Zemljine okeane, površinu Zemlje, površinu prekrivenu ledom i atmosferu kako bi se mogle pratiti i razumjeti dinamičke promjene na globalnom nivou.

Ova misija je bazirana na dva identična satelita čija je konstelacija u orbiti takva, da obezbjeđuje optimalno globalno pokrivanje površine i dostavljanje podataka.

Sa širinom zahvata od $1270 \mathrm{~km}$ i 21 spektralnih bendova, Sentinel 3 pruža globalno pokrivanje Zemljine površine svaka dva dana. Glavni fokus Sentinel 3 misije jeste praćenje okeana i površine zemlje [3].

\section{VIZUALIZACIJA GEOPROSTORNIH PODATAKA KROZ PRIMJENU GEOSERVER- A I GEOPORTALA}

Vizualizacija geoprostornih podataka se odnosi na način prikaza i predstavljanja prostornih podataka. U oblasti kartografije je došlo do značajnih promjena koje se odnose na prikupljanje, obradu, analizu i interakciju sa velikom količinom prostornih podataka i u budućnosti će te promjene biti još veće. Glavni razlog tih promjena jeste pojava i razvoj interneta.

Razvojem interneta i informatike počinju se primjećivati promjene u svakoj struci zastupljenoj u današnjem društvu. $\mathrm{Na}$ primjer u geodeziji i geoinformatici je sve češća upotreba geoinformacionih sistema (GIS-a), tj. aplikacija koje omogućavaju pregledanje i izmjenu prostornih podataka.

Jedna organizacija koja je značajna po tome što radi na otvorenosti prostornih podataka jeste OGC ili punim nazivom Open Geospatial Consortium (Udruženje za otvorenost prostornih podataka).

Styled Layer Descriptor (SLD) je XML šema definisana od strane Open Geospatial Consortium-a (OGC) i služi za opisivanje layer-a koji se pojavljuju na karti. Korišćenjem SLD-a moguće je definisati renderovanje (prikazivanje na odgovarajući način) vektorskih i rasterskih podataka.

\subsection{GeoServer}

GeoServer je serverska aplikacija otvorenog koda (eng. open source) napisana u programskom jeziku Java, čija je svrha prikazivanje i uređivanje prostornih podataka. Zbog činjenice da je pisana u Java-i, omogućeno je njeno jednostavno postavljanje i izvršavanje na bilo kom široko korišćenom operativnom sistemu (Windows, Linux, Mac OS X i drugi), što doprinosi popularnosti aplikacije.

Osnovni cilj GeoServer-a jeste da predstavlja čvor $u$ okviru slobodne i otvorene infrastrukture prostornih podataka [4].

\subsection{Geoportali}

Geoportal predstavlja ciljno mjesto za prikaz geoprostornih podatka, njihov pregled, izmjenu i pretragu. Portal je web sajt koji predstavlja pristupnu tačku mnogim resursima i okruženje koje omogućava organizacijama, korisnicima podataka i onima koji dostavljaju podatke da objedine sadržaje i da ih međusobno dijele.

\subsection{Open Layers}

OpenLayers 3 predstavlja open source grafičku biblioteku koja omogućava integrisanje dinamičkih mapa na bilo koji web sajt. Ova grafička biblioteka je bazirana na JavaScript-u. JavaScript je skriptni jezik koji se koristi za razvoj web baziranih klijentskih aplikacija. Podržavaju ga svi internet pretraživači sa ciljem da se kreira poboljšan korisnički interfejs i dinamički web sajtovi [5].

Primjena OpenLayers 3 biblioteke za kreiranje interaktivnih web mapa je veoma jednostavno i pošto se radi o open source tehnilogiji njena primjena je besplatna. Velika prednost primjene ove biblioteke jeste to što podržava $i$ moderne mobilne telefone tako da omogućava i kreiranje aplikacija za mobilne telefone.

\section{PRAKTIČNA PRIMJENA}

Praktični dio ovog rada se sastoji iz nekoliko osnovnih koraka a to su: prikupljanje podataka u obliku satelitskih Sentinel 3 snimaka, čija obrada se vrši u programima SNAP i QGIS kako bi bili u odgovarajućem obliku da bi se mogli skladištiti u bazu podataka i publikovati na server. Za formiranje baze podataka u ovom radu je korišćen PostGIS (PostgreSQL), a server za publikovanje podataka jeste GEOSERVER. Svrha ovog rada jeste da se geoprostorni podaci vizualizuju i predstave na nekom web sajtu u obliku geoportala primenom open source programa.

\subsection{Prikupljanje podataka i područje od interesa}

Prvi korak jeste prikupljanje podataka, odnosno snimaka koji će se koristiti za klasifikaciju. Snimci koji se koriste su multispektralni snimci Sentinel-3 platforme, koji su dostupni na sajtu Evropske svemirske agencije (ESA). Da bi imali mogućnost pristupa snimcima potrebna je registracija na The Sentinels Scientific Data Hub ${ }^{1}$ stranici.

Nakon registracije i prijave na sajt, podaci se mogu pretraživati ili prema ključnim riječima (npr. naziv države) ili obuhvatanjem područja od interesa. Da bi se suzila pretraga moguće je koristiti filtere kao što su datum akvizicije snimaka, vrsta platforme (Sentinel-1, Sentinel-2 i Sentinel-3), tip proizvoda, polarizacija kod Sentinel-1 snimaka i procenat oblačnosti kod Sentinel-2 snimaka.

\footnotetext{
1 https://scihub.copernicus.eu/dhus/\#/home
} 


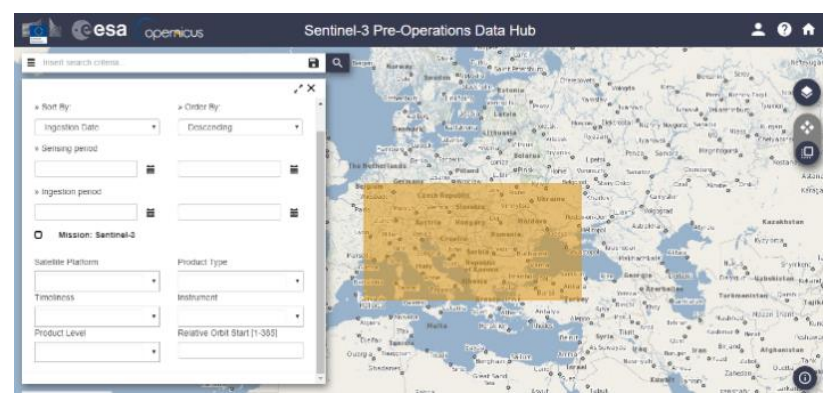

Slika 1. Izgled prozora za pregled dostupnih snimaka

Za potrebe ove analize ukupno je obrađeno 33 snimka iz 2017 godine. Područje od interesa jeste područje Vojvodine (Republika Srbija), sa posebnim naglaskom na područje Fruške gore i Novog Sada.

\subsection{Obrada satelitskih snimaka u programu SNAP}

SNAP arhitektura je idealna za obradu i analizu snimaka observacije Zemlje zbog sledećih tehnoloških inovacija: proširivost, prenosivost, modularna i bogata platforma klijenata i mogućnost primjene Graph Processing Framework koji omogućava obavljanje više funkcija u jednom koraku.

Za potrebe ovog rada potrebno je da se analizira i obradi veliki broj Sentinel 3 snimaka.

Pošto je ponavljanje cjelokupne analize za svaki pojedinačni snimak dosta dugotrajno, moguće je formirati graf koji će da sadrži sve korake metodologije i primjenom opcije Batch processing, obraditi sve snimke u jednom koraku.

Prvi korak u postupku analize Sentinel 3 OLCI snimaka jeste ukljanjanje oblaka sa snimaka, odnosno piksela koji predstavljaju oblake, za ovo se primjenjuje opcija IdePix Processor.

Drugi korak u procesu analize jeste da se odredi vrijednost NDVI (Normalized Difference Vegetation Index) za svaki piksel za koji je na osnovu IdePix Processor-a određeno da nije oblak. Za ovaj proces se koristi opcija BandMath, gdje se unosi formula za NDVI indeks.

Sledeći korak u procesu analize jeste da se smanji, odnosno redukuje veličina snimka i da se obuhvati samo područje od interesa. Poslednji korak ovog grafa jeste opcija Reproject.

Sentinel 3 OLCI proizvodi su dostupni kao georeferencirani podaci na Zemljinoj površini. Primjenom ove opcije je moguće koristiti određenu kartografsku projekciju i na taj način osigurati da svi podaci imaju iste prostorne karakteristike.

Nakon što se izvrši obrada ovih podataka potrebno je pomoću opcije Collocate da se više prostorno preklapajućih snimaka spoji u jedan proizvod kako bi se mogla vršiti dalja analiza.

Nakon kolokacije snimaka, da bi se oni na jednostavniji način mogli koristiti potrebno je izvršiti Band Subset, odnosno izdvojiti samo relevantne bendove koji su u ovom slučaju bendovi sa vrijednostima NDVI indeksa, i pomoću opcije Band Math izračunati njihovu srednju vrijednost (Mean NDVI), koji će na kraju i da se koristi za analizu.

Rezultat obrade podataka $u$ softveru SNAP je raster predstavljen na slici 2.

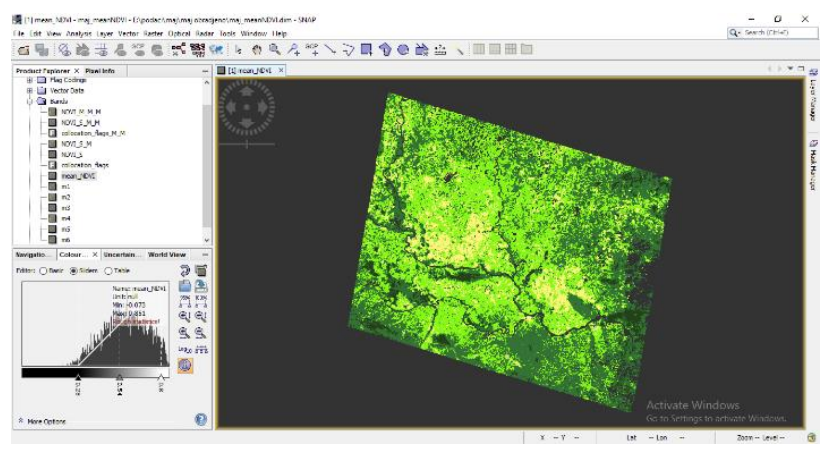

Slika 2. Rezultat obrade podataka u softveru SNAP

Nakon obrade snimaka, dobija se konačni snimak za svaki mjesec čije vrijednosti piksela predstavljaju srednju vrijednost NDVI indeksa.

\subsection{Obrada podataka u programu QGIS}

Open source program QGIS se u ovom radu koristi kako bi se izvršila poligonizacija prethodno sačuvanog rastera $u$ SNAP-u. Postupak poligonizacije predstavlja prevođenje rastera u vektor. Izgled tih vektorskih podataka, odnosno rezultat obrade podataka u softveru QGIS je predstavljen na slici 3 .

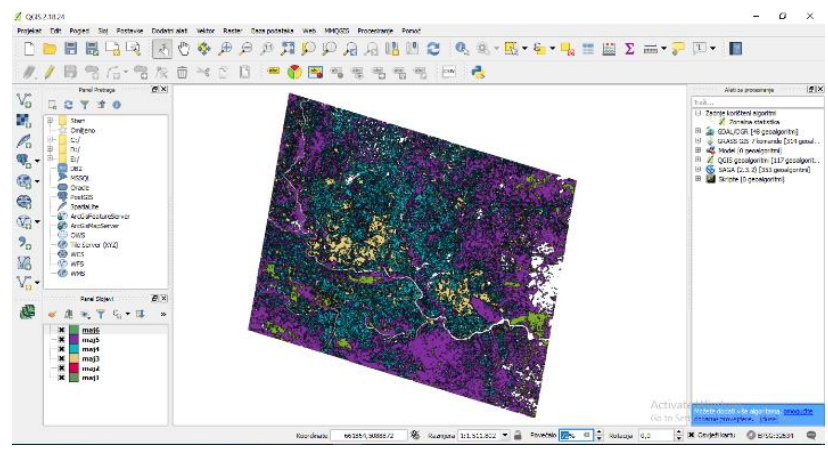

Slika 3. Vektorizacija rastera $u$ QGIS

\subsection{Kreiranje baze podataka i publikovanje podataka na server}

Osnovna struktura koja je primijenjena u ovom radu za vizualizaciju geoprostornih podataka jeste troslojna arhitektura koja se sastoji od baze podataka, servera i geoportala. Baza podataka se koristi za skladištenje podaka koje želimo da prikažemo, dok server služi za publikovanje tih podatka i kako bi se na zahtjev korisnika na geoportalu vizualizovali traženi podaci.

Za kreiranje baze podataka se koristi softversko rješenje PostgreSQL sa PostGIS ekstenzijom.

Podatke iz baze je potrebno zatim publikovati na server. Za potrebe ovog rada se koristi GeoServer.

Podaci koji su publikovani na GeoServer -u se sada mogu koristiti i vizualizovati na nekom geoportalu.

Kreirani geoportal se sastoji od:

- zaglavlja,

- legende u kojoj su dati rasponi NDVI indeksa

- Checkbox-a u kome je moguće izabrati prikaz određenog mjeseca u toku godine

- Play i Pause opcije pomoću kojih je moguće pokrenuti timeline, gdje se u zavisnosti od odgovarajućeg mjeseca vrši prikaz vrijednosti NDVI indeks.

Izgled geoportala je predstavljen na sledećoj slici. 


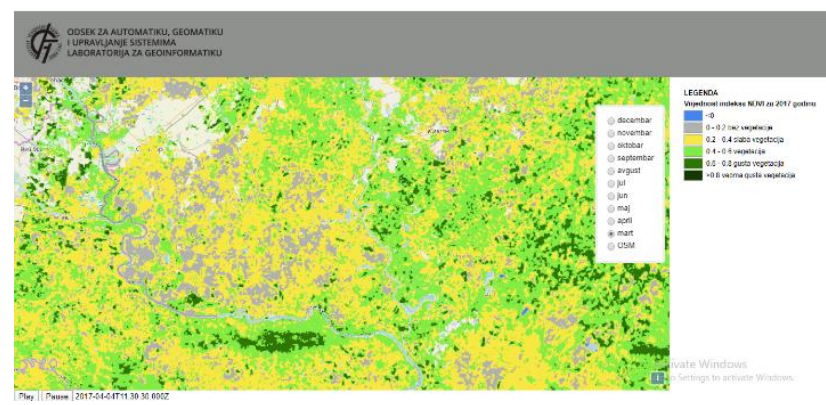

Slika 4. Izgled geoportala

\section{ZAKLJUČAK}

Ubrzanim razvojem oblasti daljinske detekcije i lansiranjem velikog broja satelitskih platformi, koji se koriste $\mathrm{u}$ ovoj oblasti, omogućen je sistematičan i vjeran prikaz Zemljine površine. Snimci koje dobijamo sa različitih satelitskih platformi nam pružaju ogromnu količinu informacija koje se mogu primijeniti u različitim oblastima ljudskog života, a naročito za praćenje promjena na zemljinoj površini kao što su: vizuelno praćenje topljenja leda na planinama, promjena vegetacije u toku godine, šumskih požara ili širenja bolesti.

Jedna takva platforma, koja nam obezbjeđuje veliku količinu informacija u formi multispektralnih snimaka je Sentinel-3 platforma, čiji snimci su iskorišćeni za analizu u ovom radu. Izvršena je njihova obrada i klasifikacija u okviru open-source programa SNAP i QGIS, za potrebe praćenja promjena Zemljine površine $u$ toku jedne godine. Za praćenje promjena je iskorišćen NDVI indeks (Normalized difference vegetation index).

Vizualizacija geoprostornih podataka se odnosi na način prikaza i predstavljanja prostornih podataka. Aplikacije koje služe za vizualizaciju geoprostornih podataka su uglavnom komercijalne prirode $\mathrm{i}$ često veoma skupe, pa ih krajnji korisnik pribavlja samo ako će od njih imati veliku finansijsku korist.

Prednost primjene vizualizacije geoprostornih podataka $u$ odnosu na tradicionalni pristup kartografije jeste što se primjenom vizualizacije na mapi može pronaći veći broj informacija i dodatnih objašnjenja, za razliku od obične mape, koja sadrži samo one informacije koje su nam u tom trenutku vidljive. Takođe veliku prednost koju vizualizacija pruža u odnosu na konvencionalne metode jeste korišćenje i mijenjanje stila mapa u relanom vremenu, kako bi se prilagodio izgled mape potrebama korisnika
Kako bi se potencijalni korisnici motivisali za korišćenje webGIS i web kartografskih aplikacija, potrebno je za početak smanjiti finansijske izdatke, utrošeno vrijeme i ostale resurse korišćene u razvoju ovakve aplikacije. Ovde na red stupaju aplikacije otvorenog koda (eng. Open source tehnologies), koje omogućavaju puno brži, a samim tim i jeftiniji razvoj, između ostalih, webGIS i web kartografskih aplikacija.

Svi softveri koji su primijenjeni u ovom radu su open source tipa i imaju veliku prednost u odnosu na slične sofrtvere komercijalnog tipa, jer u poređenju sa njima daju podjednako dobre rezultate, a besplatni su i slobodno dostupni svim korisnicima.

\section{LITERATURA}

[1] Dr. Miodrag Regodić. Daljinska detekcija kao metod prikupljanja podataka o prostoru. Vojnotehnički glasnik, 2008

[2] Internet: Sentinel Hub by Sinergise. NDVI (Normalized Difference Vegetation Index). Laboratory for geographical information. https://www.sentinelhub.com/eoproducts/ndvi-normalized-differencevegetation-index

[3] Internet: European Space Agency. http://www.esa.int/About_Us/Corporate_news/ESA f acts

[4] Internet: GeoServer. http://geoserver.org/.

[5] Thomas Gratier, Paul Spencer, Erik Hazzard. Open Layers 3. Packt Publishing, 2015

\section{Kratka biografija:}

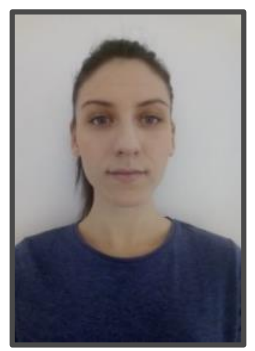

Mara Božinović rođena je u Salzburgu, Austrija, 22.04.1994. godine. Osnovne akademske studije završila na Fakultetu tehičkih nauka - oblast Geodezija i geomatika $\mathrm{i}$ iste godine upisala master studije na istom fakultetu. 